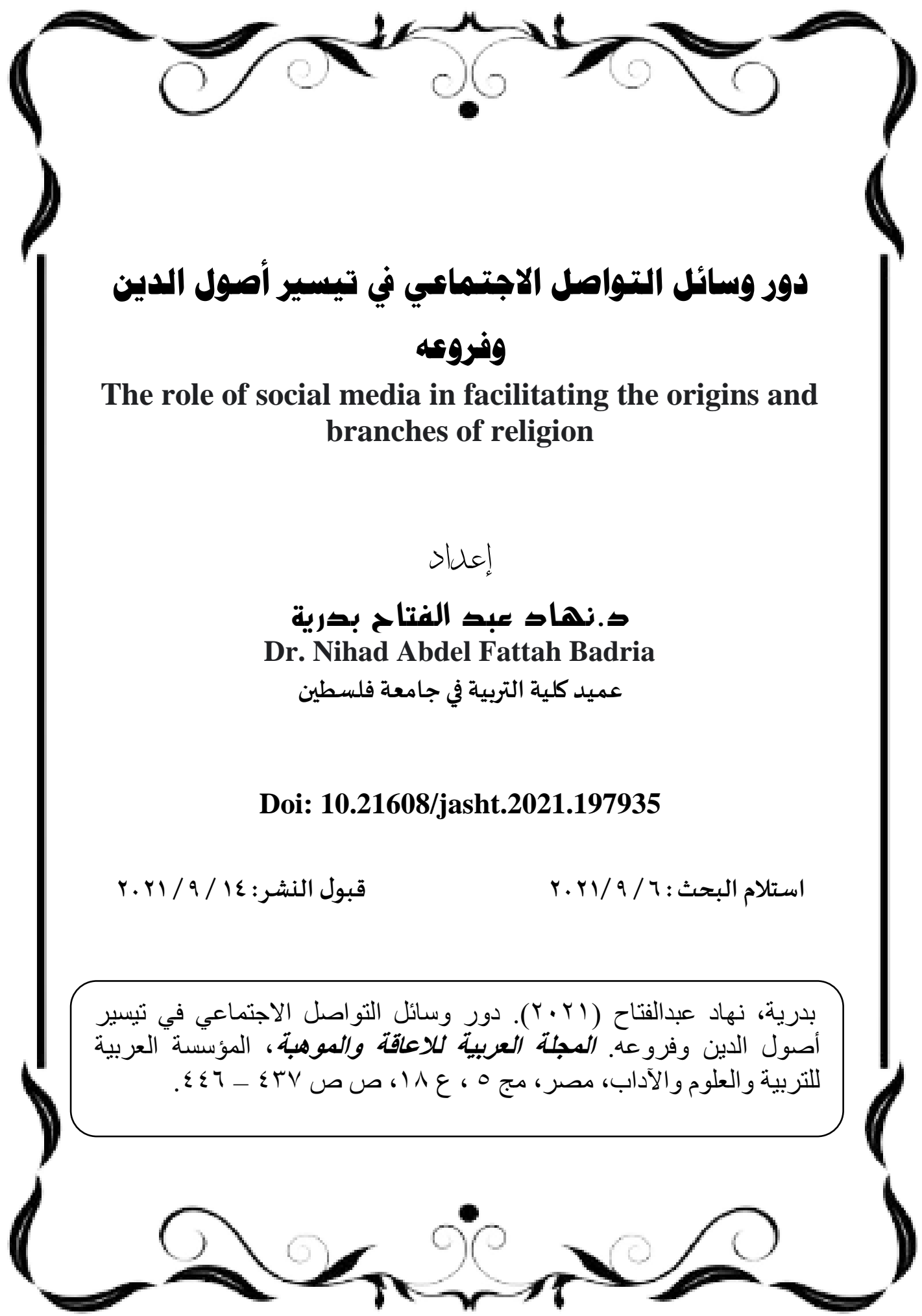




\section{دور وسائل التواصل الاجتماعي في تيسير أصول الدين وفروعه}

يتناول هذا البحث محور الخدمات الثرعية والدينية لذوي الإعاقة في المؤتمر

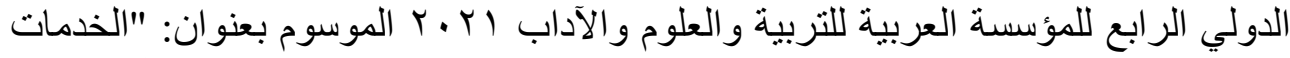

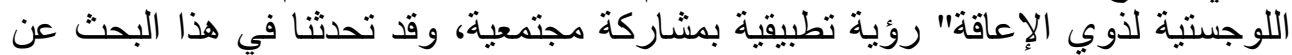

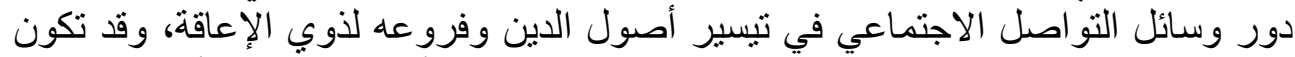

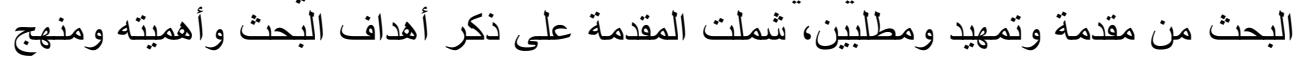

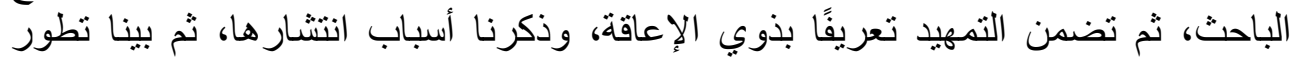

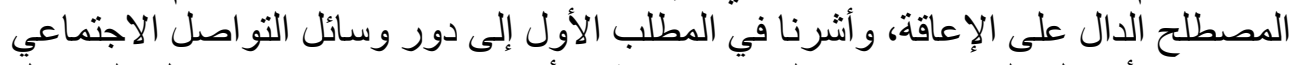

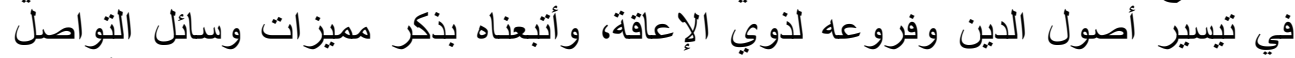

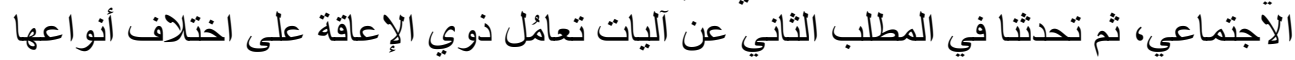

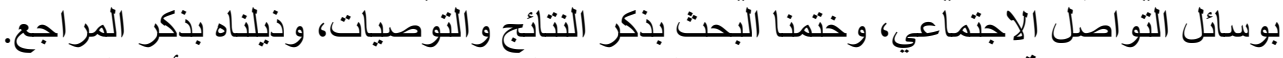

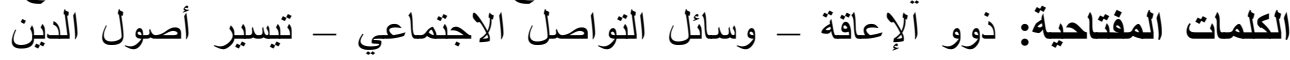
وفرو مله.

\section{Abstract:}

This research deals with the theme of Sharia and religious services for people with disabilities in the Fourth International Conference of the Arab Foundation for Education, Science and Arts 2021, entitled: "Logistics services for people with disabilities" is an applied vision with community participation. In this research, we talked about the role of social media in facilitating the origins and branches of religion for people with disabilities, The research may consist of an introduction, a preface and two requirements. The introduction included a mention of the research aims, its importance and the researcher's approach. Then, the introduction included a definition of people with disabilities, and we mentioned the reasons for its spread, Then we explained the development of the term indicative of disability, and we referred in the first requirement to the role of social media in facilitating the origins and branches of religion for people with disabilities, We followed it by mentioning the advantages of social media, then we talked in the second requirement about the mechanisms of dealing with people with disabilities of all 
kinds through social media, and we concluded the research by mentioning the results and recommendations, and we appended it with references.

\section{Key words:}

Social media. people with disabilities- Facilitate the origins and branches of religion -

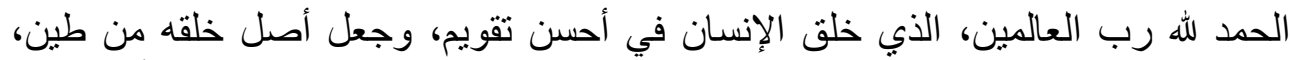

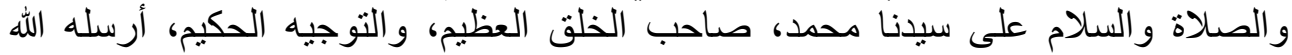

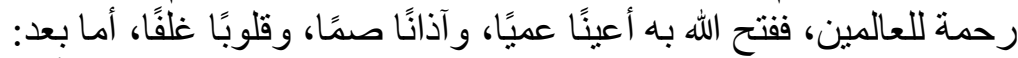

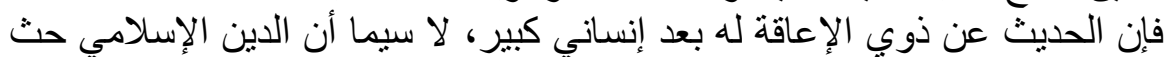

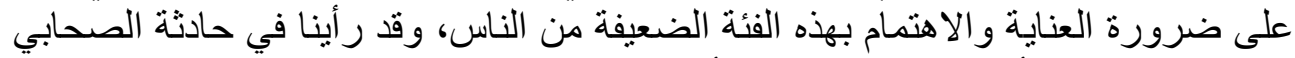

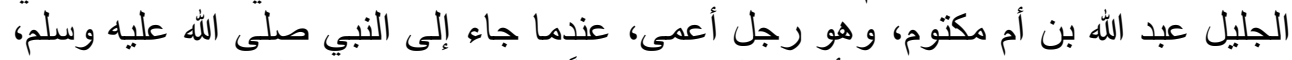

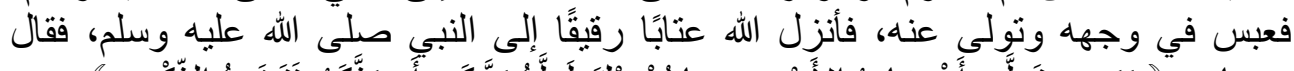

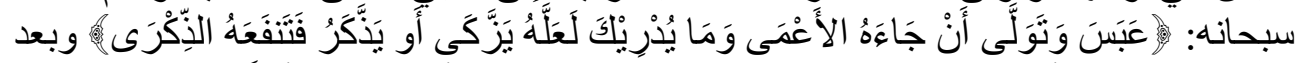

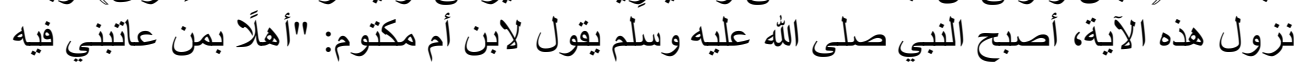

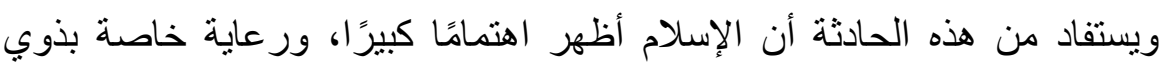

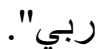

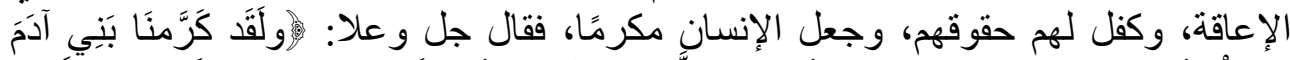

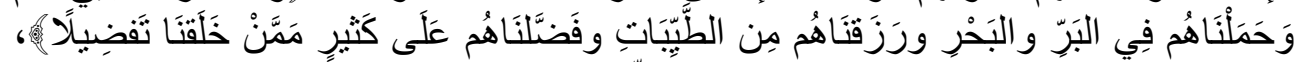

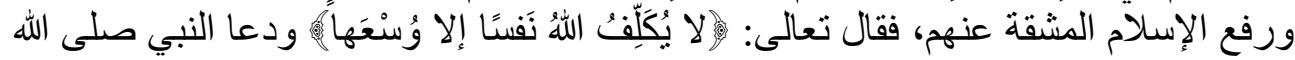

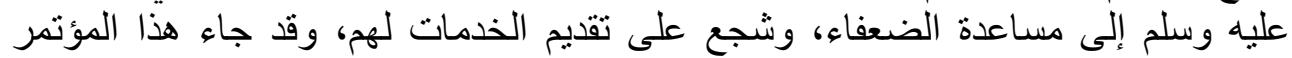

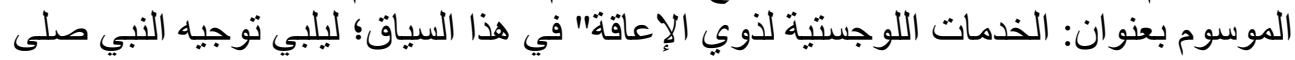

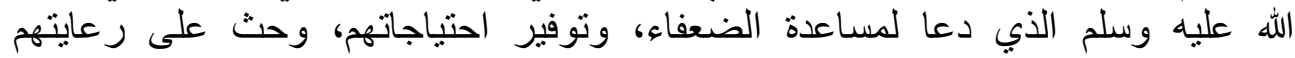
و الاهتمام بهم؛ للوصول إلى رؤية مجتمعية ترى النور في الجو انب التطبيقية و العملية في كل

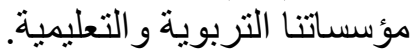

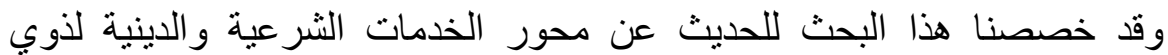

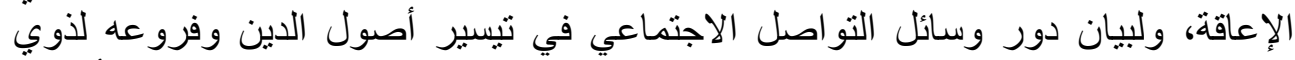

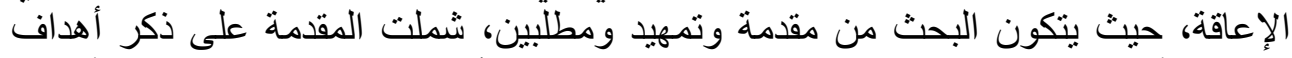

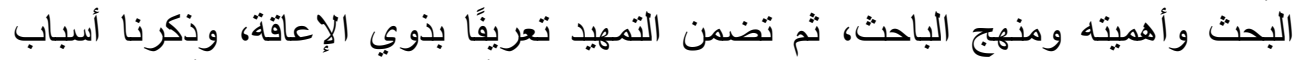

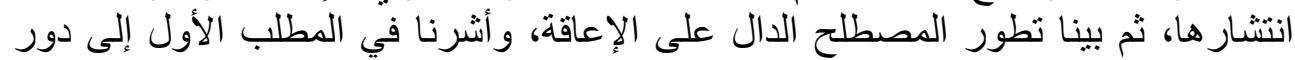

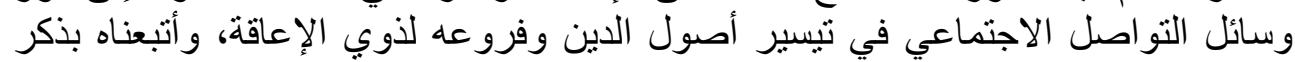




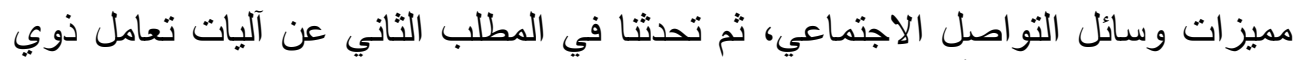

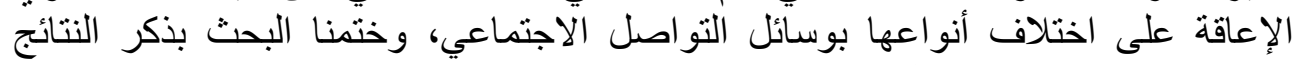

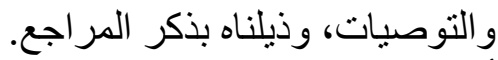

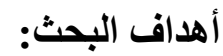

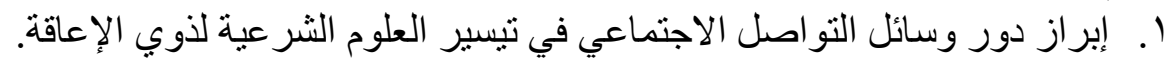

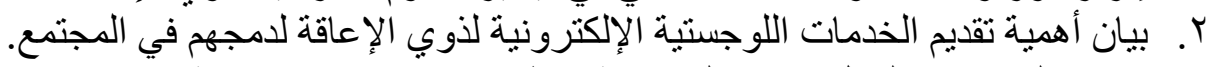

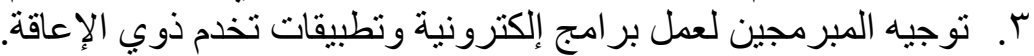

$$
\text { أهمية البحث: تكمن أهمية البحث في أنه: }
$$

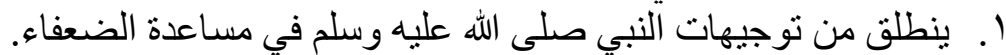

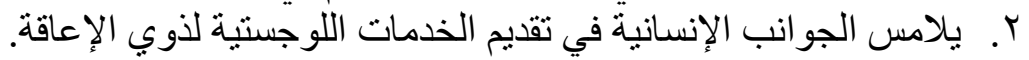

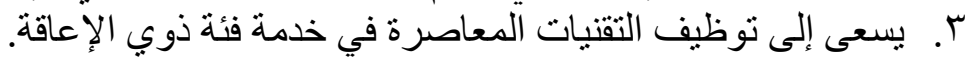
منهج البحث:

اتبع الباحث المنهج التاريخي و الاستقر ائي الذي يتناسب مع طبيعة الموضوع محل البحث.

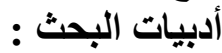

\section{من هم ذوو الإعاقةت الإن}

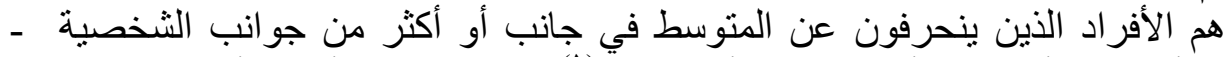

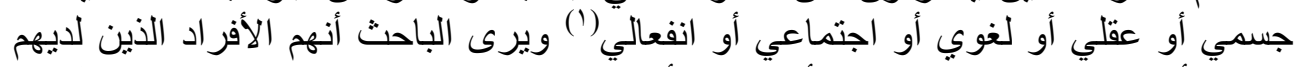

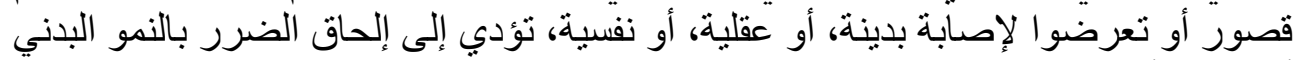

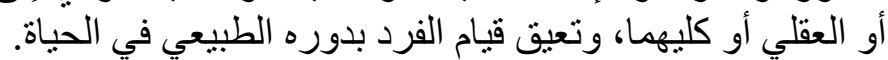

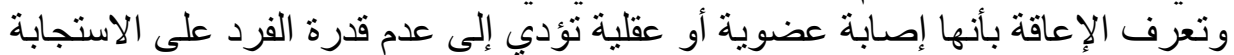
للمؤثرات البيئية أو التكيف معها بشكل طبيعي نتيجة لمشكلات سلوكية أو أو جسمية أو الو الونية

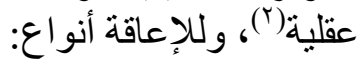
- الإعاقة الحركية: هي التي تلتعلق بالحركة و التنقل من مكان إلى آخر .

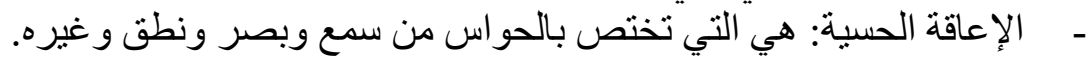

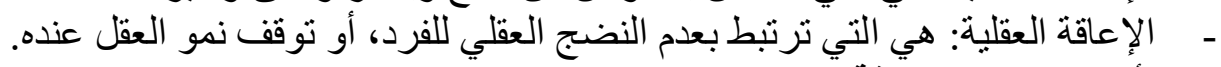

\section{أسباب وجود الإعاقة:}

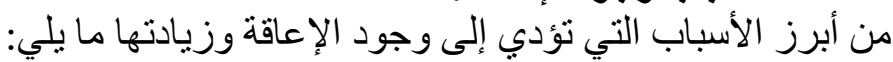

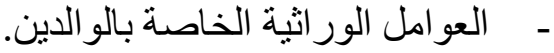

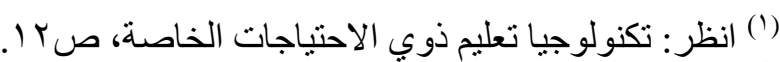

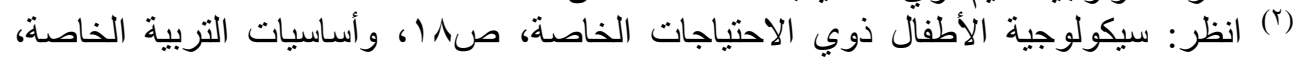




$$
\begin{aligned}
& \text { - موء التخذية. } \\
& \text { - } \\
& \text { - الحو ادث الخطيرة. } \\
& \text { - }
\end{aligned}
$$

لقد تعددت المسميات التي أطلقت على الاعة هذه الفئة، حيث ظهرت القات أسماء متعددة، منها:

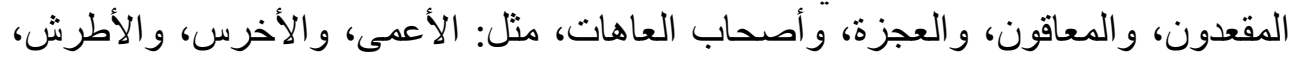

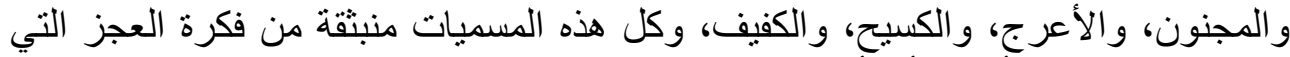

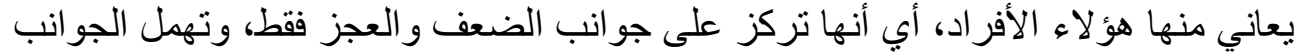

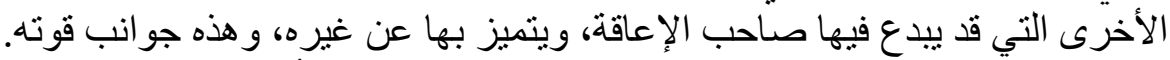

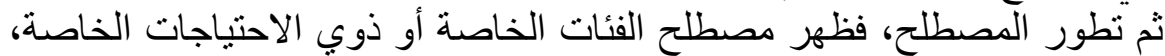

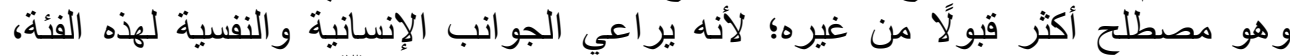

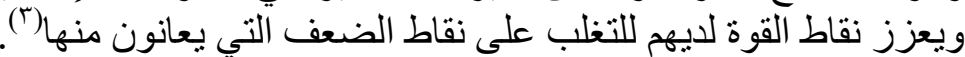

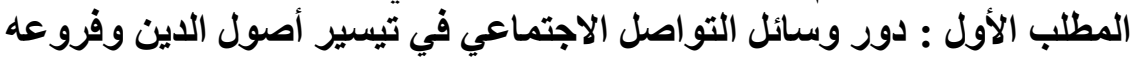

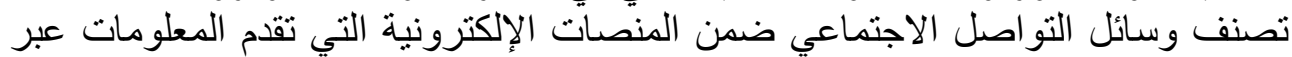

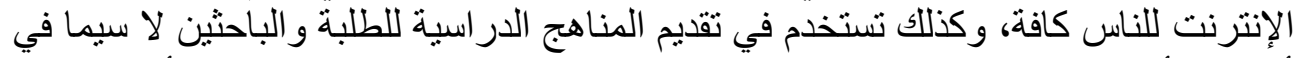

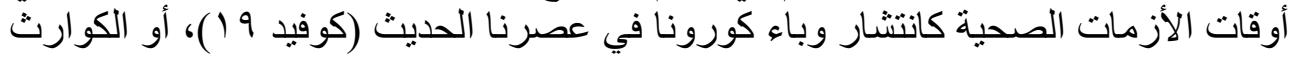

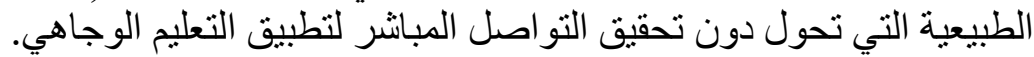

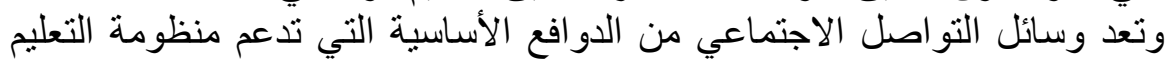

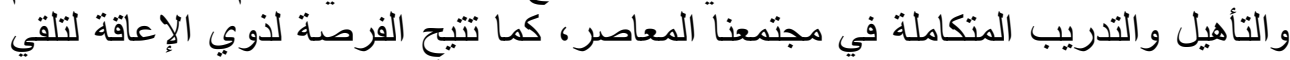

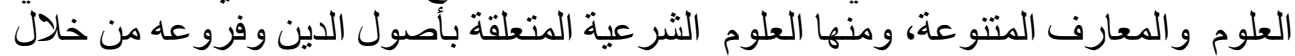

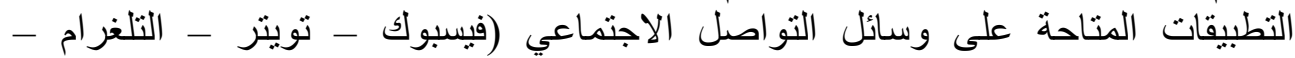

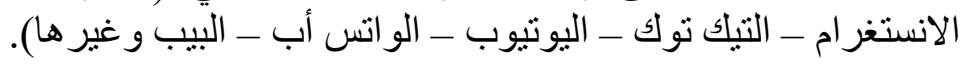

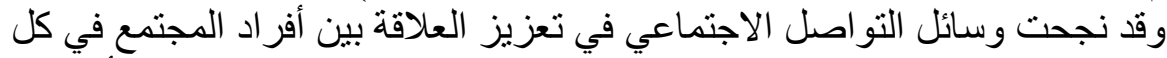

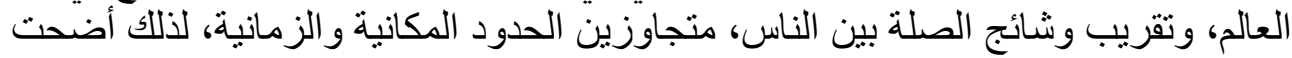

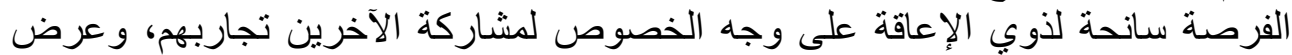

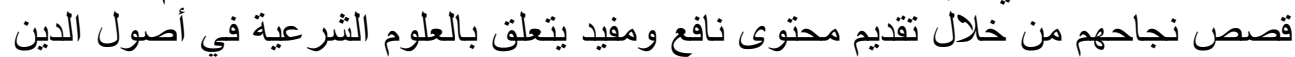
وفرو عه، وبذللك تتحقق مجمو عة من الفو ائد المهمة لذون لذوي الإعاقة، منها:

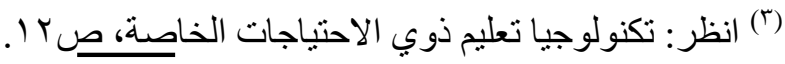




\section{* * مشاركة أصحاب الإعاقة لقصص نجاح خاصة:}

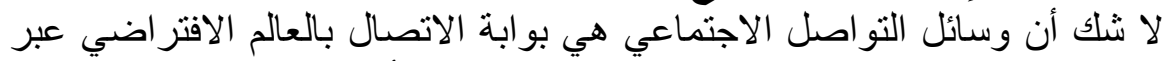

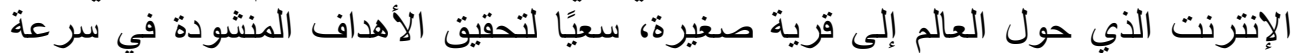

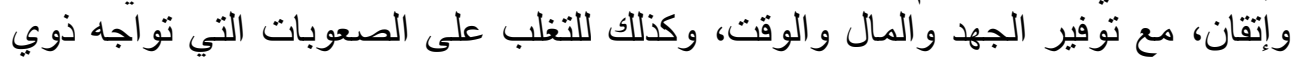

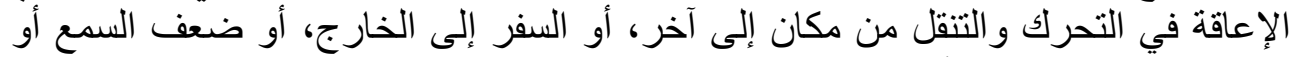

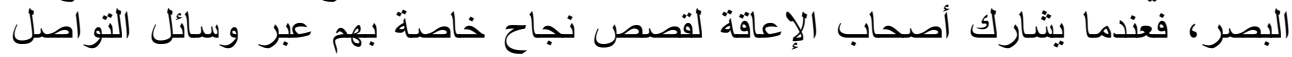

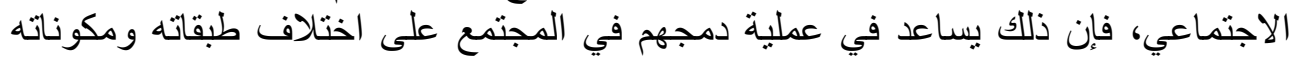

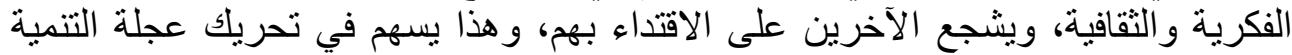

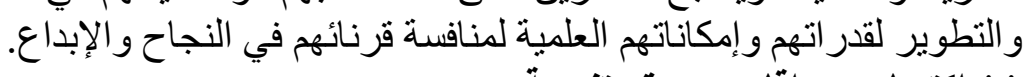

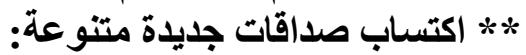

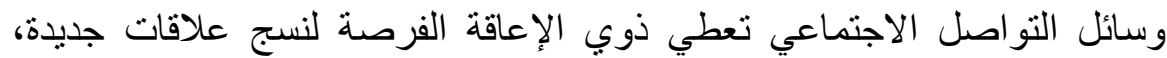

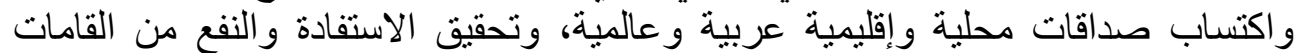

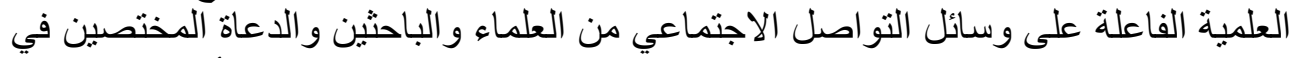

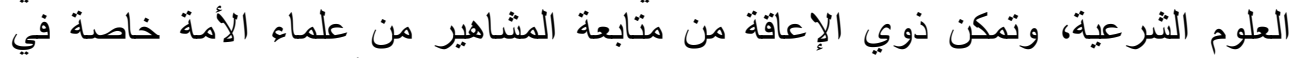

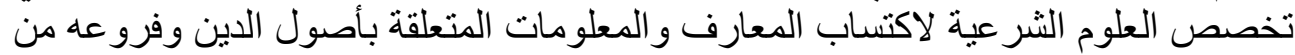

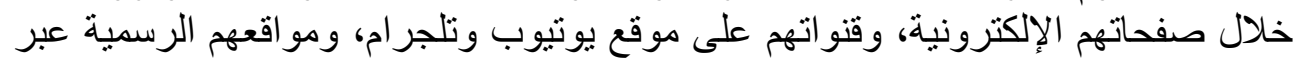

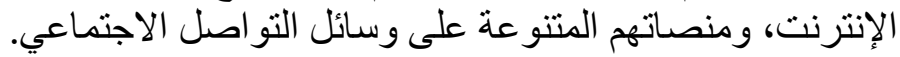

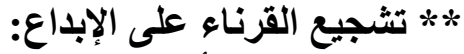

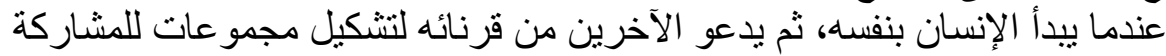

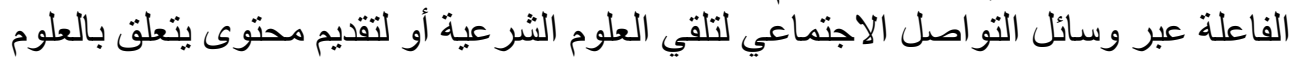

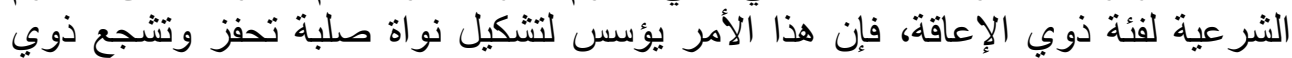

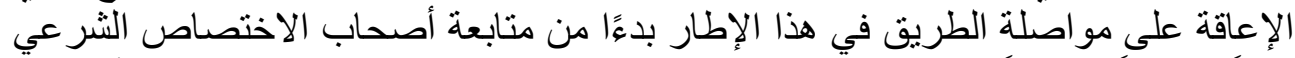

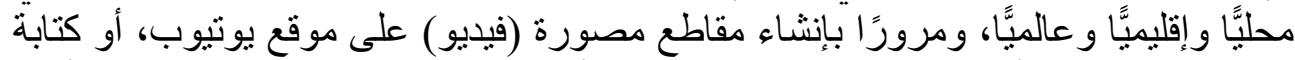

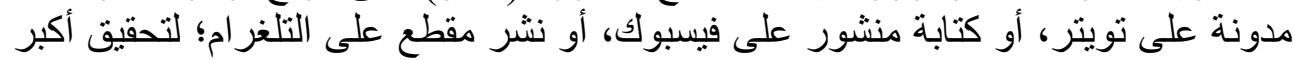

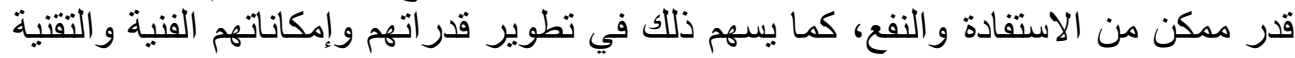

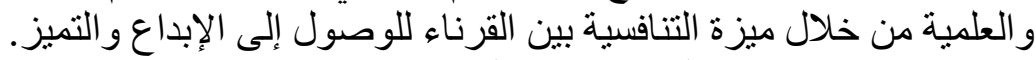

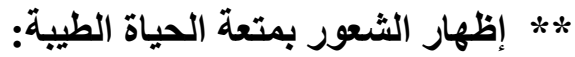

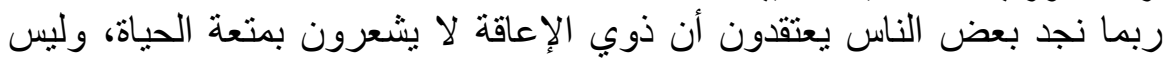

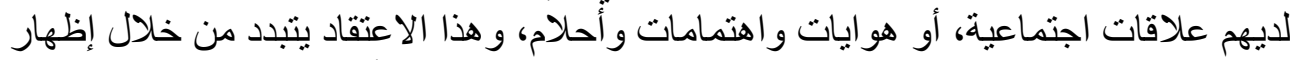

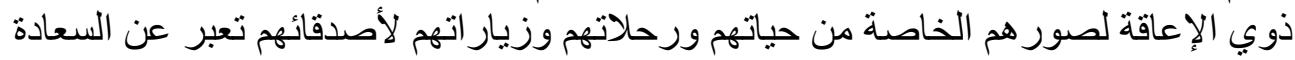

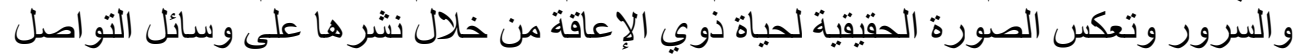


الاجتماعي، ومشاركة الآخرين لهذا الثُعور، و التفاعل مع هذه الصور بمزيد من الحيوية

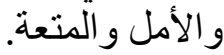

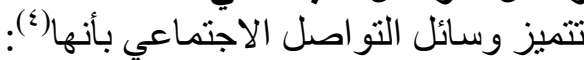

ا. تعتمد على شبكة الإنترنت لتفعيل الاتصال بالآخرين، ولتحقيق الاستفادة من المحتوى

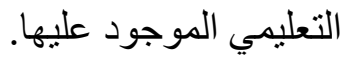

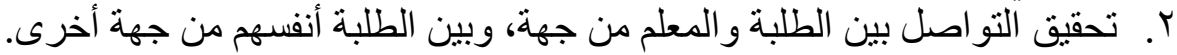

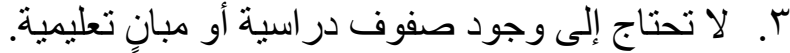

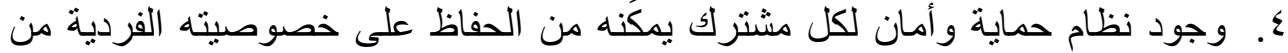

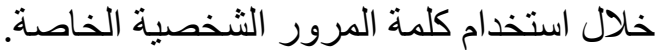

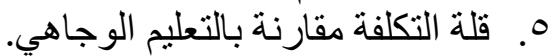

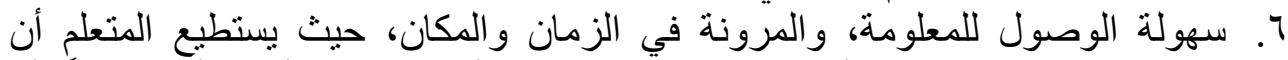

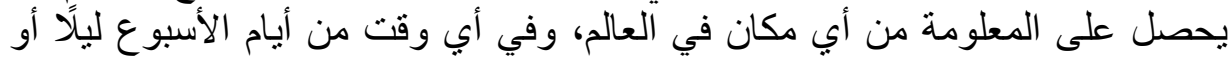
نهارًا بما يتناسب معله المعله

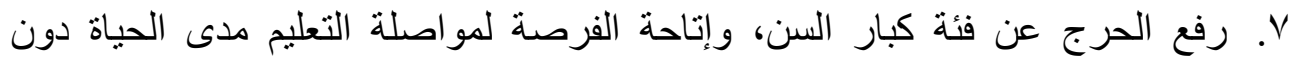
الالتز ام بعمر زمني معين.

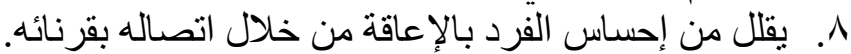

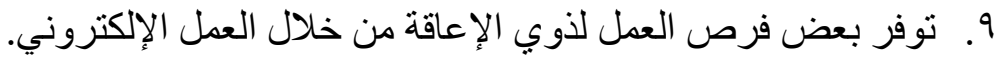

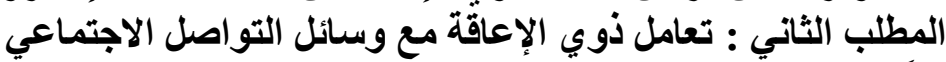

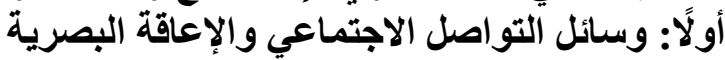

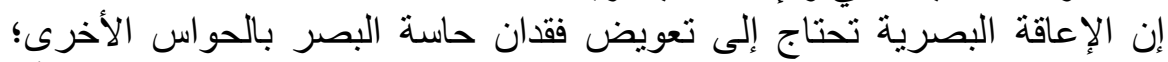

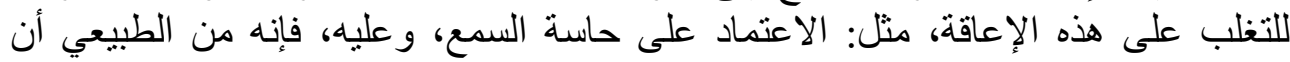

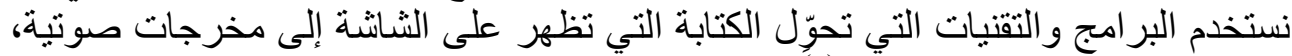

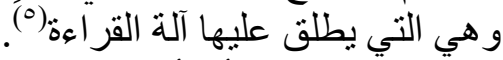

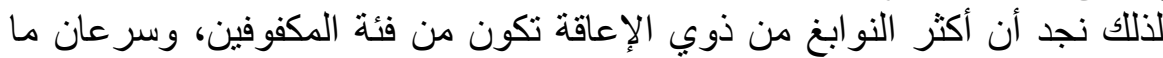

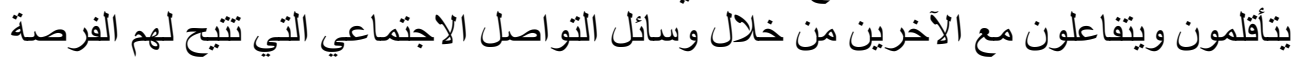

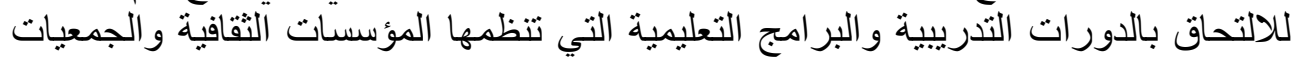

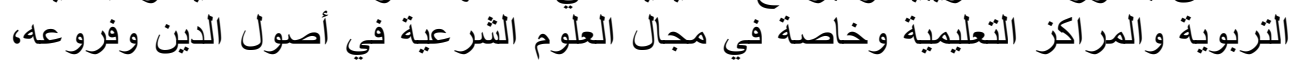
كتعريفهم بالدين الإسلامي وأركان الإيمان، وشر في وح العقيدة الإسلامية من توحيد الألو هية

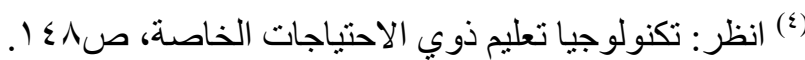

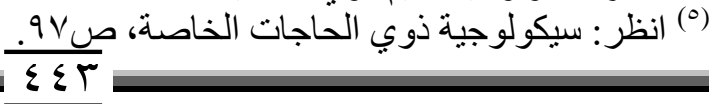


و الربوبية و الأسماء و الصفات، والتعريف بالمناسك و الثعائر الدينية من صلاة وزكاة وحج

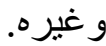

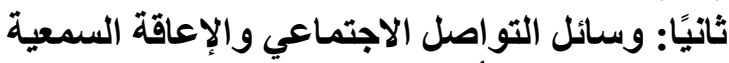

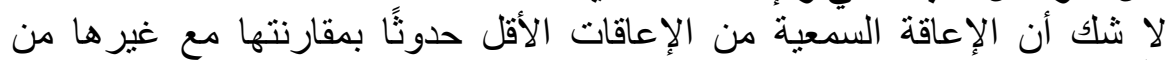

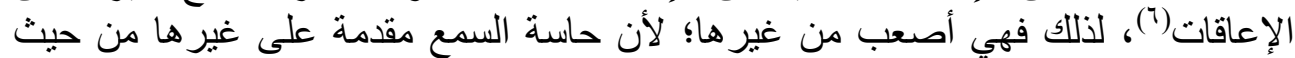

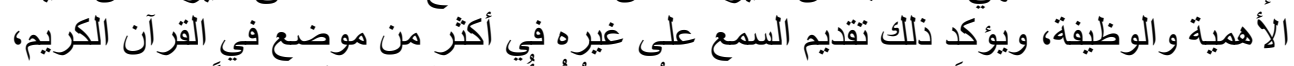

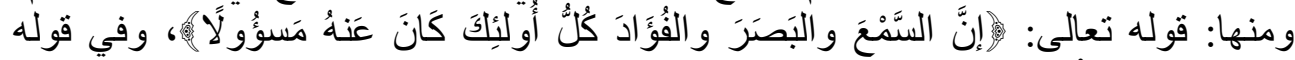

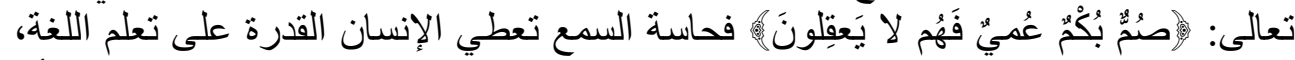

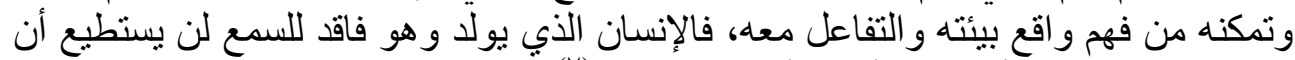

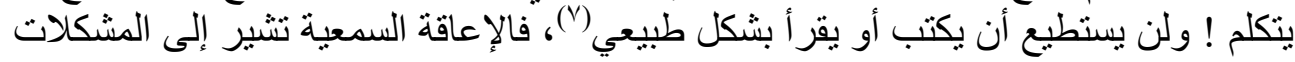

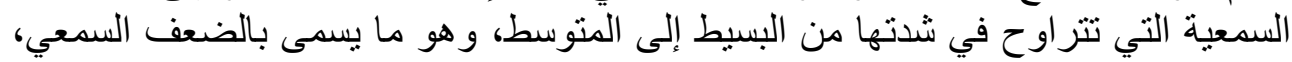

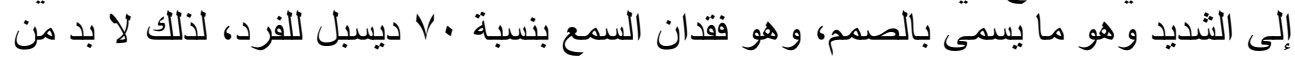

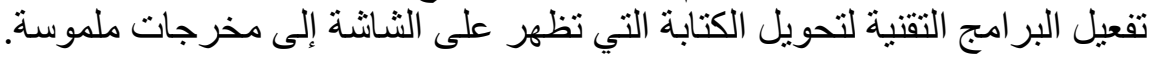

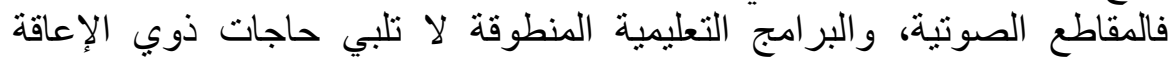

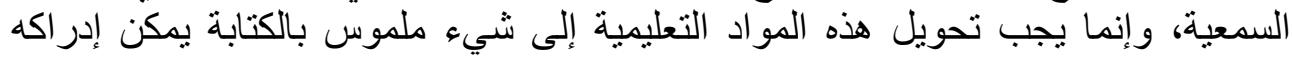

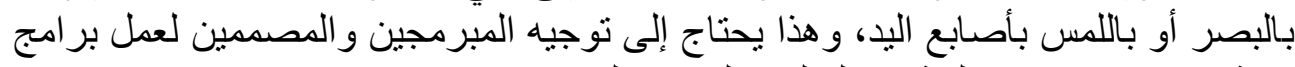

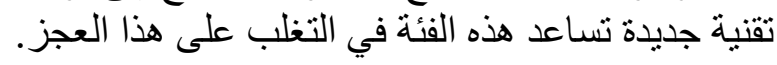
نتائج البحث: ا. و وسائل التواصل اصل الاجتماعي لها دور كبير في توفير خدمة التعليم والتدريب لذوي الإعاقة

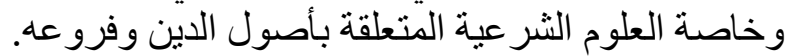

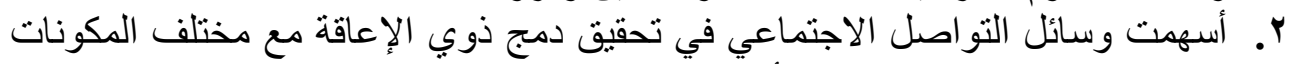

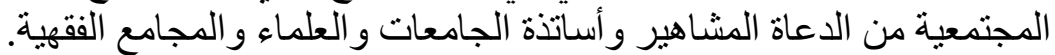

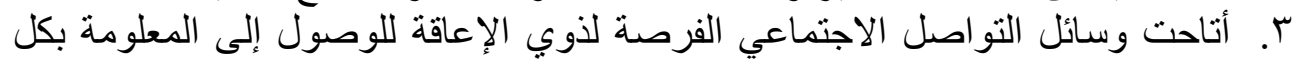
يسر وسهولة. توصيات الباحث: ت تونة 1. توجيه المبرمجين والمصممين لمو اصلة جهدهم في ابتكار تطبيقات إلكترونية تخدم ذوي

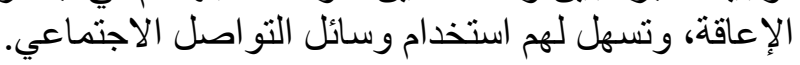

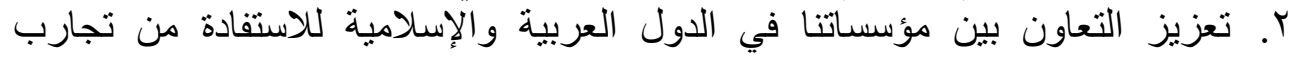

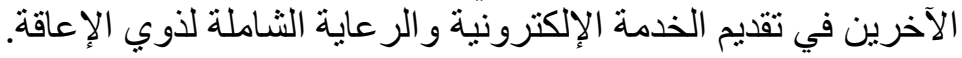




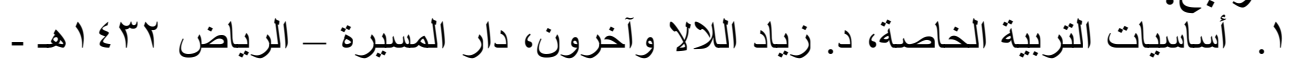
إسع:

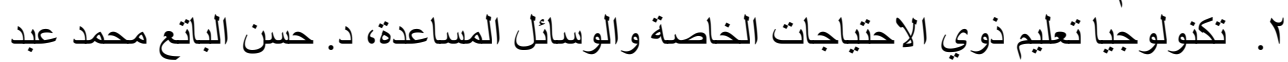

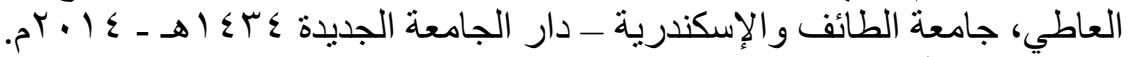

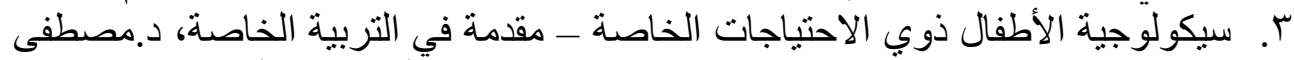

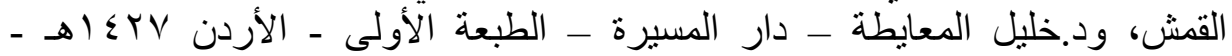

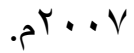

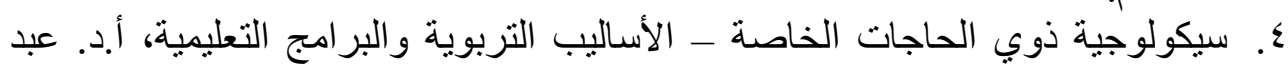

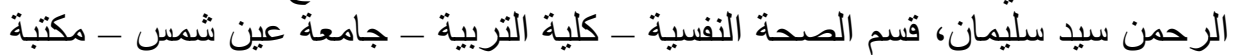

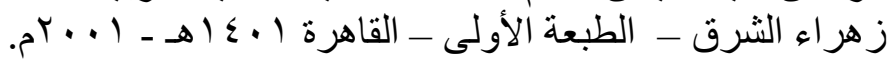


